the purpose of having a pterygium removed from the good eye. The operation was done and within two hours an acute, fulminating glaucoma developed in that eye, resulting in complete lose of vision. I wish to bring out the point of danger in making any kind of an operation upon an eye that is predisposed to glaucoma. It may have occurred in this case from the cocain, the operation, or the mental impression produced upon the patient, which $I$ am quite sure has much influence in these cases.

Dr. Houmes-I would like to ask Dr. Gould how often he advises the massage?

Dr. Gould-Just as of ten as the tension goes above normal. The manner of massage is, in my estimation, of importance, that is, the rubbing must be very slow and clear around the outer edge of the eye. You can make great pressure if you will only go slowly and make no quick movements.

Dr. J. E. Minney, Topeka--I was recently called to a case of glaucoma where I desired to do an iridectomy, but they ref used. I inquired into the history of the case and ordered quinin. The homeopathic physician who was in attendance said that he had put the patient on quinin and that he was giving five grains every four hours. This treatment was continued and the patient was cured. It was a case of malarial glaucoma. I never thought so much about glaucoma until two years ago, when the pastor of a little church in Kansas was stricken with total blindness. He called for the family physician because of the pain, and the physician injected morphin, which gave tem. porary relief. He came to me in April, two months later, with the right lens dislocated in to the anterior chamber, high ten. sion and much pain. The eye was enucleated, and he did well. He returned to his charge, but six months lator I had to remove the other eye. It is the saddest case that ever came under my observation. I think if those who are teaching med. ical students can only teach them two things, that is, to recognize iritis and glaucoma, they will be amply repaid.

Dr. C. D. Wescote, Chicago-I would like to ask Dr. Gould, or others who have used massage, if they succeed in preserving the fields as well as the vision in these cases? I have had a patient under treatment for two years whose vision has remained $2 \%$, and whose tension is kept down, but the field has gone on contracting.

Dr. Gould - The field in the several cases I have had, and especially the one I referred to, remains normal, but $I$ have only tested her with the finger for the past year.

Dr. Tномpson-Some of my patients, in spite of the mas sage, have gone blind, but so have some of my iridectomy cases. A great many cases have been benefited and the field has not contracted, but in spite of any treatment you will have some of the patients go blind.

\section{THE FIELD OF BINOCULAR FIXATION OR THE HOME OF THE GUIDING SEN- SATION OF THE RETINA.}

Presented to the Section on Ophthalmology, at the Forty-ninth Annual Meeting of the American Medical Association, held at Denver, Colo., June 7-10, 1898.

BY G. C. SAVAGE, M.D.

PROFESSOR OF OPHTHALMOLOGY IN MEDICAL DEPARTMENT VANDERBILT UNIYERSTTY. NASHYILIE, TENN.

A private letter from Dr. Francis Valk of New York has led me into a further study of the guiding sensation of the retina. In my book "New Truths in Ophthalmology," I have emphasized its importance as master of the extrinsic and intrinsic eye muscles, but it seems to me now that I did not place enough emphasis on it. The part of Dr. Valk's letter which bis led me to undertake this communication is as fol. lows: "I have been reading your book lately and have been very much pleased with the work; but as I have read it a question has come into my mind that I want to ask you about. I note that in your chapter on Accommodation and Convergence, you lay great stress and importance on the guiding sensation of the eyes, and there I agree with you; but if this function is so important, and I believe it is, then may I ask: Of what value is any test for the power or balance of the ocular muscles that deprives the eyes of this most important function? In my own mind I am convinced that we must treat our cases of muscular difficulties according to nature's demands on the eyes, and we must not deprive the eyes of their most important function to understand their balance."

For many years I have taught my classes in the Medical Department of Vanderbilt University that, if we had but one eye, there would be no need for the extrinsic ocular muscles; that all of these muscles exist that there may be binocular single vision. In simplifying the study of these extrinsic ocular muscles I teach that the recti, in the final results of their action, are concerned only with the visual axes; that the superior and inferior recti, if acting in harmony, will keep these visual axes in the same plane, and that the lateral recti muscles will so control these axes as to make them intersect at the point of the object to be fixed.

I believe further that, if these recti muscles could thus control the visual axes without effecting any other change, there would be no need for the oblique muscles in eyes not affected by oblique astigmatism. Because of the fact that the inferior recti can not depress the eyes without, at the same time, effecting divergence above of the vertical meridians of the eyes, and the superior recti can not elevate the plane of the visual axes without, at the same time, converg. ing above the vertical meridians, the necessity for the oblique muscles in all eyes for counteracting this torsion is at once made clear: hence I have always taught that the oblique muscles exist for the purpose of keeping the naturally vertical meridians parallel, which I have termed the simple function of the obliques. But in oblique astigmatism, with the meridians of best curvature converging or diverging above, the obliques are forced to perform their complicated function, which is to slightly converge or diverge the naturally vertical meridians. Therefore the common function of all the extrinsic ocular muscles is the production of binocular single vision. I believe these muscles are subject to one common master, which I bave termed the guiding sensation of the retina. I believe that the home of this guiding sensation in the retina can be outlined, and that within this area the guiding sensation, in a normal condition of the ocular muscles, has the complete mastery of them all. I believe its throne to be the fovea centralis of the yellow spot of Soemering, and that its scepter sways over an area of the retina somewhat of the shape outlined in the accompanying cut. An image displaced 4 degrees to the nasal side of the macula by means of an 8.degree prism marks the inner boundary of this area; and, that vision may not be doubled, the guiding sensation commands the exter. nal rectus to abduct the eye so that the macula may be brought under the displaced image. An image displaced to the temporal side of the macula 15 to 20 degrees, by means of a prism of 30 or 40 degrees, practically marks, on the horizontal retinal meridian, the 
temporal limit of this area. To prevent double vision the guiding sensation can command, through the brain that the eye be abducted so as to bring the macula under the displaced image. Likewise a displacement of an image on the line of the vertical retinal merid. ian $1 \frac{1}{2}$ degrees above or below the macula by means of a 3.degree prism, base up and down respectively, would
mark the upper and lower boundaries, on this meridian, of the retinal space constituting the domain of the
guiding sensation. To overcome the diplopia the guid. ing sensation only has to call into activity the muscles that will depress and elevate the eye. Beginning at the nasal limit, $b$, a line drawn through the upper limit, $c$, thence through the outer limit, $d$, thence through the lower limit, $e$, thence back to the inner limit, $b$, encloses this retinal space. An image displaced anywhere within this space in one eye, without any displacement in the other, can be fused with the non-displaced image in the fellow eye at the com. mand of the guiding sensation, the proper muscle

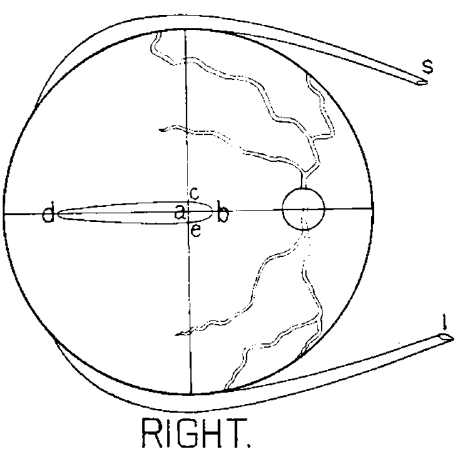

always responding to the call. Images displaced without this area can not be fused and no attempt is made at fusion, the guiding sensation having learned that its commands under such a condition will not be obeyed, or that it has no existence without this area. It remains, nevertheless, a fact, that some eyes with abnormal condition have a smaller retinal area for the effective work of the guiding sensation, while in others, in which the extrinsic muscles are of more than what is considered normal strength, this area is larger. Therefore it may be stated that, in individual cases of heterophoria, this area will have its own shape, differing from that represented in the cut. The drawing is intended to represent eyes whose abduction is 8 degrees, whose sursum and deorsum duction is 3 and whose adduction is from 30 to 40 degrees. Between the lines, it may be stated here, that the diplopia which would be effected by a torsion of the eyes by the superior and inferior recti muscles, and the diplopia caused by oblique astigmatism, are each counteracted by the oblique muscles in obedience to a command from the guiding sensation.

If this teaching as to the guiding sensation be true, what should constitute the methods of examination to determine the condition of the extrinsic eye muscles? It should be granted in the beginning that, if there is orthophoria of all of these muscles, the visual axes and the vertical meridians will bear the correct relationship to each other, although the vision of one eye may be excluded by means of an opaque disc interposed. No test for heterophoria can be fully relied upon, unless the displaced image in one eye is thrown entirely without the retinal area occupied by the guiding sensation; for the eye under test should be taken wholly from under the control of the guiding sensation that the eye muscles might place the eye in the position of equal tension of all of the eye muscles, which means the position of rest. There should be no displacement of image in the other eye. ${ }^{1}$ At once it would appear that the test by means of Maddox' rod could not be the best, for, in some part, the streak of light must invade the domain of the guiding sensation, necessitating some sort of effort on the part of the guiding sensation to effect the fusion of some part of the false image with the true. For lateral heterophoria it would seem that a prism suffi. ciently strong to throw the displaced image entirely beyond, either above or below, the outlined area would be a sine qua non. This would take, unquestionably, the lateral muscles from under the control of the guiding sensation when the eye under test would swing itself into a position of equal tension of the externus and internus, thus causing the displaced image to stand to the right or to the left of the vertical plane

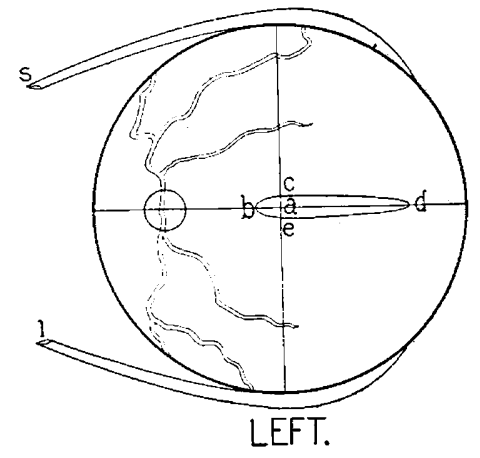

of the true object. The distance should be measured by prisms and that measurement would show the quantity of the lateral error, whether esophoria or exophoria. Likewise, in testing for vertical heterophoria the image in one eye should be displaced to the nasal side of the macula, entirely beyond the retinal area under the control of the guiding sensation, when the eye, no longer under the control of the guiding sensation, would be elevated or depressed so as to give equal tension to the two vertically acting muscles. The measurement of the elevation or depression should be taken in the usual way by means of prisms, and thus could be reached a correct understanding as to the quantity of the hyperopia or cataphoria of that eye.

Objection to the double prism test would appear to be that one of the displaced images might fall within the retinal area of the guiding sensation and hence might lead to some error; but if the prisms are sufficiently strong both images can be thrown so far outside of this area as to make the test perfectly reliable. After having made the test for ascertaining the bal. ance or imbalance of the eye muscles, the intrinsic power of the recti muscles should always be taken. By this it is meant that prism after prism should be used up to the point where fusion is no longer possible. If a case has been found to be orthophoric and the abduction is 8 degrees, and the sursum and deorsum duction each 3 degrees, no condition could be more desirable. This test would show that, within the area under control of the guiding sensation, images can be easily fused by means of obedience on the part of the

1 The author has just now (September 24) perfected a phorometer on this principle. 
extrinsic muscles to the command of the guiding sensation. Again, suppose that a case has been found to be exophoric and the abduction is only 8 degrees, or less, there is at once a clear indication for doing nothing at all to the external rectus muscle of either eye, but the attention, in such a case, should be turned to the interni, and the condition should be corrected either by exercise of these muscles or by shortening one or both of them.

While the phorometer will always show the kind of heterophoria with which we have to deal, the duction test should always be relied upon as a correct guide in our efforts to bring relief.

\section{DYNAMICS OF THE EXTRINSIC OCULAR MUSCLES.}

Presented to the Section on Ophthalmology at the Forty-ninth Annual Meeting of the American Medical Association, held at Denver, Colo., June 7-10, 1898.

BY FLAVEL B. TIFFANY, M.D. KANSAS CITY, MO.

Some years ago, when I became especially interested in the subject of the dynamics of the extrinsic ocular muscles, I read and reread the chapters on this subject. As the subject to me at that time was abstruse and puzzling I tested repeatedly the strength of the ocular muscles in my own case, and as I could only get a fractional amount of prism dynamics compared with that given in the books I concluded that mine was an exceptional case, that the strength of my extrinsic ocular muscles was greatly below the normal; but when I began to test some of my patients and found that their abduction as a rule only amounted to 6 or 8 degrees, while the adduction rarely exceeded 20 or 30 degrees, which was much less than was stated in the text-books, I began to think that there was some mistake. Either I had not thoroughly comprehended the subject and had used different methods or else the statements in the books were mis. leading. But it was not until Dr. J. M. Banister, major and surgeon U. S. A., read his paper that I was fully persuaded to make a more careful search in the subject.

Last winter I examined 100 medical students (seniors) who were fully impressed with the importance of giving eqact answers that the real conditions might be obtained. The examinations were carefully made with square prisms, Stephens' phorometer, Maddox rod and double prism test. My associate, Dr. George E. Bellows, assisted me in making the tests and compiled the tables following.

POWER OF ABDCCTION.

$\begin{array}{lllllllllllllll}\text { No. of cases: } & 1 & 1 & 18 & 20 & 32 & 5 & 14 & 2 & 2 & 1 & 1 & 1 & 1 & 1=100\end{array}$

Unusual cases as regards relative powers.

A.--Abduction greater than adduc- $\mid$ B.-Abduction equal or nearly Case, No. Add. Abd. Condition.

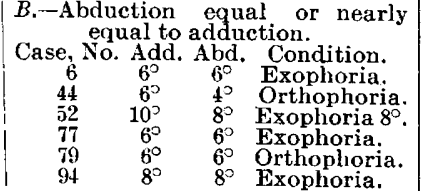

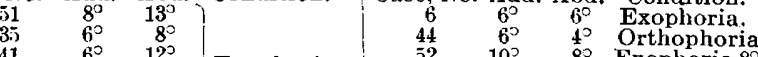

$$
\begin{aligned}
& \begin{array}{rrr}
41 & 6^{\circ} & 8^{\circ} \\
6 & 8^{\circ} & 12^{\circ} \\
6 & &
\end{array} \quad \text { Exophoria. } \\
& 81 \\
& 8^{\circ} \mathrm{J} \\
& 9
\end{aligned}
$$
power of abduction $6.26^{\circ}$ tion, $2.16^{\circ}$

POWER OF ADDUCTION.

10 degrees and under

10 to 20 degrees.

20 to 30 degrees.

17 cases

30 to 40 degrees.

51 cases

50 degrees and over

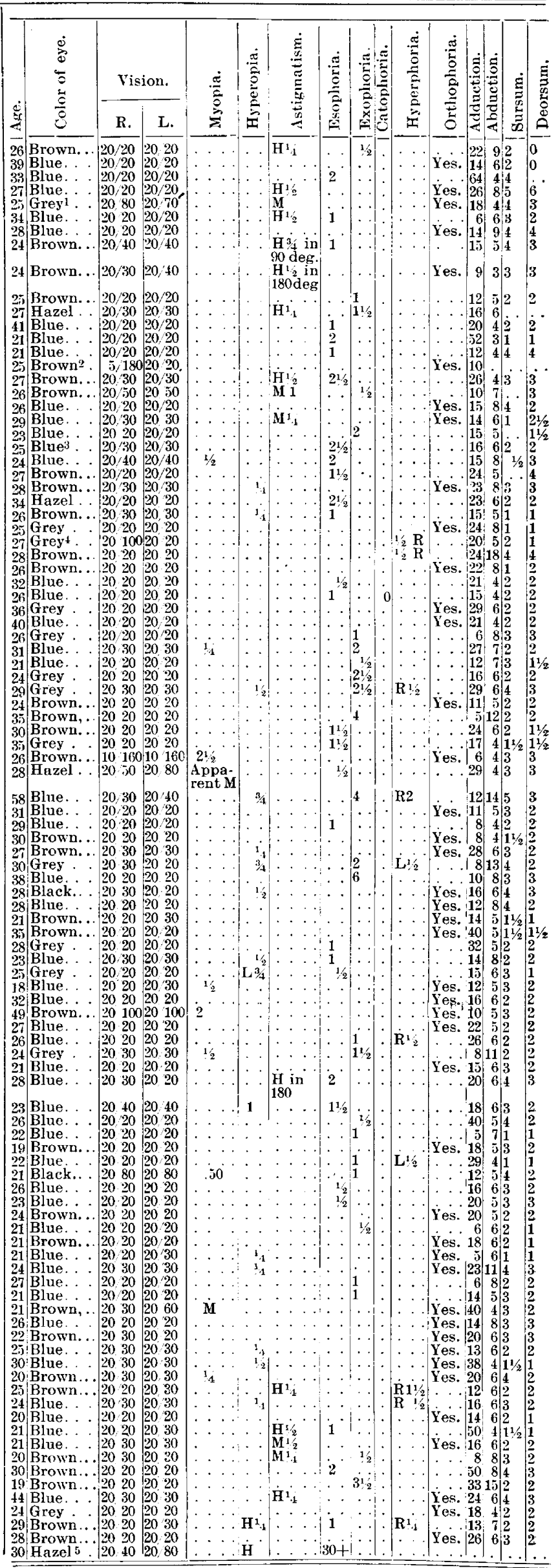

